\title{
The Development of a Sustainable Caribbean Invention and Innovation Centre at The University of Trinidad and Tobago
}

\author{
${ }^{1}$ Prakash Persad, ${ }^{1}$ Aaron O. Ameerali, ${ }^{2}$ Cilla T. Benjamin \\ ${ }^{1}$ The University of Trinidad and Tobago \\ ${ }^{2}$ The University of the West Indies
}

\begin{abstract}
This paper describes the process whereby the Caribbean Invention and Innovation Centre (CIIC) was established and launched in Barbados, the Dominican Republic, Jamaica, Suriname, and Trinidad and Tobago. The advantage of the CIIC being located in The University of Trinidad and Tobago is to provide students at both the undergraduate and postgraduate levels with exposure to and experience in the developing of products, from the idea to prototyping and marketing. Furthermore, postgraduate students will benefit from being actively involved in commercially driven research thus leading to industry ready graduates. The key output of such a facility would also lead to the formation of new manufacturing SMEs which would create employment for the country and fulfill the mandate of The University of Trinidad and Tobago, the National Policy on community development and deliver on the Millennium Development Goals.
\end{abstract}

\section{Introduction}

At present, economic drivers in both developing and developed countries around the world show the trend toward the development of technology based industries, both in terms of production processes and output. While Trinidad and Tobago's traditional petrochemical industries are well established, quite mature and will continue to serve as the primary economic drivers, it is only through the actual introduction, development and nurturing of new, sustainable industries that Trinidad and Tobago will be able to support the need for an economic transformation from a hydrocarbon based economy to a modern and sustainable non - energy economy.

In recognizing the need for establishing a University - Industry synergy, the Mechatronics Group at The University of Trinidad and Tobago (UTT) has taken the initiative to establish the Caribbean Invention and Innovation Centre (CIIC) at its O’Meara and San Fernando Campuses.

The establishment of the CIIC was co-funded by the Centre for Development and Enterprise (CDE) located in the Dominican Republic. This project introduced the CIIC's design services and prototyping laboratories to 53 SMEs and 21 intermediary organizations in Barbados, Dominican Republic, Jamaica, Suriname and Trinidad and Tobago over the period May 12 to October 20, 2011.

The CIIC was facilitated by the Barbados Manufacturers' Association in Barbados, Asociación de Industrias de la República Dominicana, Inc. (AIRD) in the Dominican Republic, the Jamaica Manufacturers' Association in Jamaica, and the Suriname Business Forum in Suriname.

The CIIC's mission is “To provide a facility for the designing and building of prototypes and new products throughout the Greater Caribbean for use by manufacturing entrepreneurs and inventors. The CIIC has the ultimate objective of encouraging and supporting a spirit of invention and innovation throughout the Caribbean, leading to an eventual increase in the numbers of innovative small- and medium-sized enterprises.”

\section{Services Provided by the CIIC}

The Caribbean Invention and Innovation Centre is equipped to provide any of a number of services inclusive of the provision of training on the product development process, starting from product conception, provision of advice on the technical feasibility and marketability of product ideas, engineering drawing and design, creation of digital prototypes and the creation of physical prototypes.

Its support to students, inventors, entrepreneurs and innovators includes any of the following:

- Idea evaluation

- Testing of proof of concept via digital simulation

- Testing of proof of concept via small scale model production

- Developing designs

- Prototype production

- Batch production of new and existing products

- Consultancy Services

The CIIC is equipped with significant physical resources which may be used in accomplishing its objectives. These resources include: 
- $\quad$ Advanced Design Software Laboratory

- Robotics and Automation Laboratory

- Advanced Controls and Instrumentation Laboratory

- 2D Laser Cutting Machine

- Fused Deposition Modeling Rapid Prototyping Machine for the creation of Plastic Prototypes

- $\quad$ Selective Laser Sintering Rapid Prototyping machine for the creation of Metallic Prototypes

A unique feature of the CIIC being located within the UTT is that both undergraduate and postgraduate students benefit from the services offered by the CIIC. Specifically for the Manufacturing and Design Programme, students are required to design, build and test an artifact that adds value to the industry or manufacturing sector of Trinidad and Tobago.

At the first stage in the design process, after preliminary simulations, an Alpha model will be developed for further testing. Once this passes through the detailed phase, a working Beta prototype will be developed. This will then be subjected to rigorous testing before a fully validated prototype is developed and ready to move on to the business incubator and into industry. It is in this regard that the CIIC lends its services to the students in the provisional support of idea development to prototyping to the marketability of the product.

Other products that have benefited from this facility include production lines for SMEs, small agricultural machinery (e.g. mango cutter), food processing machinery (e.g roti maker), the robotic drummer and several industrial components.

A summary of the services provided by the CIIC is summarized schematically in Figure 1 below.

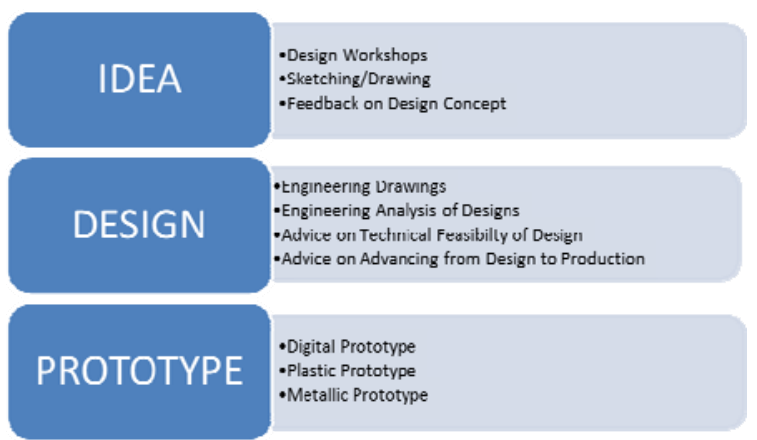

Figure 1. showing services provided by the CIIC

Even more importantly, UTT provides a Technical Team, whose members are specially skilled and experienced in each of the core service areas for the project. This team is constructed as shown in Table 1 below.
Table 1. The CIIC Technical Team

\begin{tabular}{|c|c|c|}
\hline Name & Qualification & $\begin{array}{l}\text { Area of } \\
\text { specialization }\end{array}$ \\
\hline $\begin{array}{l}\text { Professor } \\
\text { Prakash } \\
\text { Persad }\end{array}$ & $\begin{array}{l}\text { Ph.D. Mechanical } \\
\text { Engineering }\end{array}$ & $\begin{array}{l}\text { Robotics } \\
\text { Automation } \\
\text { and Energy }\end{array}$ \\
\hline $\begin{array}{l}\text { Nadine } \\
\text { Sangster }\end{array}$ & $\begin{array}{l}\text { Ph.D. Mechanical } \\
\text { Engineering }\end{array}$ & $\begin{array}{l}\text { AI Techniques } \\
\text { in Controls and } \\
\text { Manufacturing }\end{array}$ \\
\hline $\begin{array}{l}\text { Aaron } 0 . \\
\text { Ameerali }\end{array}$ & $\begin{array}{l}\text { MPhil, } \\
\text { Mechanical } \\
\text { Engineering }\end{array}$ & $\begin{array}{l}\text { Innovative } \\
\text { Manufacturing } \\
\text { Technologies }\end{array}$ \\
\hline $\begin{array}{l}\text { Kelvin } \\
\text { Loutan Jr. }\end{array}$ & $\begin{array}{l}\text { M.Sc. Mechanical } \\
\text { Engineering/PhD } \\
\text { Student } \\
\text { Mechatronics }\end{array}$ & $\begin{array}{l}\text { Design } \\
\text { Engineer }\end{array}$ \\
\hline $\begin{array}{l}\text { Jorrel } \\
\text { Bisnath }\end{array}$ & $\begin{array}{l}\text { PhD Student } \\
\text { Mechatronics }\end{array}$ & $\begin{array}{l}\text { Software } \\
\text { Engineer }\end{array}$ \\
\hline
\end{tabular}

\section{CIIC Workshop Activities}

The establishment phase of the project occurred in 2011, in five (5) countries, namely Barbados, Dominican Republic, Jamaica, Suriname and Trinidad and Tobago. In this phase, team members hosted a workshop entitled "Ideas to Prototyping" and arranged meetings with stakeholders and private consultations with inventors and innovators. Five (5) products were selected for immediate development within this phase and a pipeline of projects with commercial potential was compiled.

Day One of the workshops generally consisted of opening remarks by the CIIC Director, followed by presentations on the process of transgressing an idea through the design and prototyping phases. The afternoon session on the first day was reserved for a case study and making appointments for consultations with participants desirous of moving product ideas forward.

Day Two was reserved for private consultations. Private consultations were held with workshop participants who requested advice and further assistance with their product ideas. The meetings facilitated detailed discussions on proposed projects. In many instances, immediate preliminary feedback and technical advice on the technical feasibility and novelty of the projects were given.

Ideas suitable for progression to the prototyping phase were identified and this information was communicated to the respective inventor/innovator. In addition, workshop participants indicated a number of areas in which assistance was required. A number of these participants expressed an interest in utilizing the services offered by the Caribbean Invention and Innovation Centre for progressing their ideas to the prototype stage. 
The mission to Suriname was facilitated by the Suriname Business Forum and followed a slightly different format as the CIIC was invited to participate in the Innovative Entrepreneurship Seminar and Suriname Innovation Awards, 2011. Furthermore, on the day of the workshop, an opening ceremony with an audience of about seventy (70) persons preceded the actual "Ideas to Design" workshop.

\subsection{Barbados Activities}

The Barbados Manufacturers Association (BMA) facilitated the event and acted as co-sponsor. The response to the launch of the CIIC in Barbados was particularly encouraging with twenty-five (25) participants attending the workshop and eleven (11) individuals requesting private consultations for the following day. In addition, CIIC brochures were collected for promotion at the Barbados Manufacturers' Association Conference and two (2) workshop participants expressed interest in the UTT's Master of Science in Industrial Innovation, Entrepreneurship and Management Degree offered by The University of Trinidad and Tobago at its campus in the O'Meara Industrial Estate, Arima, Trinidad and Tobago.

The following was requested after the workshop:

- Short courses in training and design

- A programme to advance the knowledge of automation in Barbados

- An online video tour of the facilities be made available

- Assistance in arranging funding for product development from the Barbados Investment Development Corporation (BIDC) and other Business Development Corporations in the region

\subsection{Dominican Republic Activities}

The AIRD facilities were used and the workshop was attended by sixteen (16) persons.

The format used for the workshop was the same as delivered for all the previous Workshops and three (3) consultations were booked.

Furthermore, noteworthy meetings with potential partners from academia and the private sector, respectively, were held in the Dominican Republic. The CIIC team met with a representative from the Competitiveness and Innovation Centre for The Universidad Iberoamericana (UNIBE) of the Dominican Republic. Discussions were held regarding ways to collaborate, considering the CIIC's installed capacity. The UNIBE is a private non-profit institution founded in 1982.
The CIIC also met with representatives of Abordage, San Cristóbal. Abordage builds boat models, handmade by highly skilled craftsmen who work with remarkable precision. They also offer prototypes. Interest was expressed in their being an agent for the CIIC in the Dominican Republic.

\subsection{Jamaica Activities}

The workshop was held in the capital Kingston. The Jamaica Manufacturers' Association (JMA) facilitated the CIIC and the workshop was attended by ten (10) persons. The Jamaica Business Development Corporation and Small Business Association were both represented at the workshop.

Consultancy services were requested from the CIIC by workshop participants who indicated that they would pay a visit to the CIIC in Arima, Trinidad in a subsequent visit to the country in order to discuss future projects.

The Jamaica Manufacturers' Association collected promotional material from the CIIC for distribution at an upcoming conference. From the workshop, contacts were made to facilitate further alliances with the Jamaica Exporters Association (JEA), Jamaica Institute of Engineers and Jamaica Institute of Architects.

\subsection{Suriname Activities}

The programme was delivered in two sessions. An opening ceremony wherein the CIIC was introduced to a stakeholder audience of about 70 persons preceded the actual "Ideas to Design" workshop. The workshop was attended by twentyfive (25) persons. It was noted that the innovation thrust in Suriname was being led from the state, with the establishment of the Suriname Business Forum represented by nine (9) different state agencies, Ministries and private Sector Institutions as well as the Anton de Kom University of Suriname. As such, most of these entities were represented at the workshop.

\subsection{Trinidad and Tobago Activities}

The workshop for the planning and set-up phase of the project was held in Arima, Trinidad and Tobago at the O'Meara Campus of UTT, where the CIIC is based. Twenty-four (24) individuals attended and comprised twenty-three (23) participants from Trinidad and one (1) from Tobago.

\section{Results/Workshop Output}

From the potential projects, a total of five (5) were chosen for immediate development. These included a game component from Barbados, a coin 
sorter from the Dominican Republic, a tabletop molding tool and die from Jamaica, a key chain from Suriname, a boot scrubber from Tobago and a fertilizer dispenser from Trinidad.

Communication was maintained with the aforementioned clients throughout the processes and digital prototypes were created and tested. Simultaneously, a number of projects from other participants were advanced.

At the end of the first round of workshops in countries targeted in this initial phase, private consultations were held with a total of twenty-six (26) inventors/innovators whose ideas were discussed. Preliminary feedback was given by the design engineers of the CIIC. A pipeline of projects that showed potential for commercialization was compiled. This list included nine (9) projects from Barbados, six (6) from the Dominican Republic, one (1) from Jamaica, and four (4) from Suriname and seven (7) from Trinidad and Tobago.

Inventors/innovators expressed the view that the sessions and meetings had changed their perception of how products were brought to fruition. They had previously believed that the actualization of certain product ideas systematically, as demonstrated by the CIIC Team, was a concept that was not easily achievable by the average individual.

Most importantly, they were able to make the immediate link as to how the services of the CIIC could assist them in commercializing their product ideas.

Through interaction and private consultations with stakeholders, inclusive of inventors and innovators, business membership organizations, government agencies and institutions, an understanding was gained of the environment for practical intervention in commercialization of ideas in the respective pilot countries.

\section{Challenges faced by the CIIC}

The establishment phase of the CIIC was able to reach a much wider audience than originally targeted because of the overwhelming response from intermediary organizations. The fact that as many as twenty one (21) intermediary organizations were represented was encouraging since these stakeholders almost unanimously expressed the need for an organization such as the CIIC within the Caribbean.

Intermediary business organizations in all the countries covered by the project were willing to support the CIIC by promoting the services of the Centre among their members. In addition, independent inventors and innovators as well as established businesses were attracted to the workshops and expressed the desire for an even wider range of services than the CIIC is equipped to provide at present. Regional institutions were also in a position to play a meaningful role in achieving the overall objectives of the CIIC. The support of institutions was especially strong in the Dominican Republic and Suriname.

This inception phase of the CIIC has revealed the need for such a Centre, which seeks to empower individuals, many of whom have never been entrepreneurs and whose eyes are now being opened to the opportunities that may be available for them to exist in society from a position of commercial power. The scope of the CIIC's services include providing advice on sourcing local and foreign manufacturers; however the CIIC will not manage the relationship between inventors and producers.

While the aim of the CIIC is to become a selfsustaining organization within the first three (3) years, creative means for raising funds will have to be employed. This is so because many beneficiaries within the region, particularly young inventors and innovators, find it difficult to pay for prototyping, testing and verification of their product ideas, even where reduced costs are charged and free consultation is provided.

The CIIC has taken note of the fact that workshop participants polled have expressed a desire for programmes aimed at specific sectors. The provision of support for innovation in the agricultural/agroprocessing and creative industry sectors of the Caribbean seems to be a promising area for the start of the CIIC sector programmes and a welcome addition to the range of services already developed.

Other challenges identified during this establishment phase of the project centred on the fact that individuals whom the CIIC aims to empower, are in general, unable to contribute to the operating costs of the CIIC via professional fees, even reduced professional fees. The following objectives were therefore determined:

- Over the next three (3) years, CIIC would maintain the momentum gained by embarking on a comprehensive programme aimed at attaining a financially independent status, while supporting the development of new enterprises based on innovation throughout the Caribbean

- $\quad$ The CIIC would extend a hire-purchase option to young entrepreneurs who have marketable products and are ready to commercialize them

- The CIIC would negotiate royalty arrangements with inventors/enterprises requiring technical assistance in developing products

- For other categories of inventors and innovators with ideas of high potential, especially in the less developed territories, the CIIC would seek grant funding to subsidize the cost of the service. In these 
instances, assistance would be provided free of charge to the inventor or innovator, in addition to advice on having inventions protected and produced

- Vouchers would be offered to participants and agencies for the first year in each market targeted, to encourage continued use of the services

- In order to subsidize its operating expenses, the CIIC would design its own range of products such as corporate gifts, household and educational items and accessories for technological devices. These would be outsourced to regional producers and marketed by the CIIC to institutions, corporations and agencies.

- $\quad$ The CIIC would remain committed to its goal of "encouraging and supporting a spirit of invention and innovation throughout the Caribbean, leading to an increase in the numbers of innovative SMEs.”

\section{Conclusion}

The creation of new innovative SMEs native or indigenous to the island states of the Caribbean may increase the wealth of marginalized individuals in the society, and subsequently lead to greater social inclusion as access to healthcare, education, housing, and other socio-economic factors improve. As such the CIIC would continue to support innovation among non-traditional participants in the Caribbean, even if these individuals are unable to contribute to the cost of the services provided.

\section{References}

[1] CIIC. (2011). Caribbean Invention and Innovation Centre Planning and Set-Up Phase Report. O'Meara: Caribbean Invention and Innovation Centre.

[2] CIIC 2. (2011). Caribbean Invention and Innovation Centre Business Plan. O'Meara: Caribbean Invention and Innovation Centre.

[3] United Nations (2000). “55/2. United Nations Millennium Declaration.”

[4] United Nations (2001). "Road map towards the implementation of the United Nations Millennium Declaration.”

[5] United Nations (2008). "Delivering on the Global Partnership for Achieving the Millennium Development Goals.”

[6] EuropeAid (2002). "Guidelines for the use of indicators in country performance.” 